\title{
Integrating GIS into farmland preservation policy and decision making
}

\author{
David L. Tulloch ${ }^{\mathrm{a}, *}$, James R. Myers ${ }^{\mathrm{a}}$, John E. Hasse ${ }^{\mathrm{b}}$, \\ Peter J. Parks ${ }^{\mathrm{c}}$, Richard G. Lathrop ${ }^{\mathrm{a}}$ \\ a Grant F. Walton Center for Remote Sensing and Spatial Analysis, Cook College, Rutgers, \\ The State University of New Jersey, 14 College Farm Road, New Brunswick, NJ 08901, USA \\ b Department of Geography and Anthropology, Rowan University, 201 Mullica Hill Road, Glassboro, NJ 08028-1701, USA \\ ${ }^{\mathrm{c}}$ Department of Agriculture, Food and Resource Economics, Cook College, Rutgers, The State University of New Jersey, \\ 55 Dudley Road, New Brunswick, NJ 08901, USA
}

\begin{abstract}
The paper describes an experiment with the integration of geographic information systems (GIS) into farmland preservation techniques using the data and policies of Hunterdon County, NJ as a case study. The automation process incorporates a variety of factors as criteria for evaluating properties for a purchase of development rights. The spatially explicit criteria include evaluations of the soils, neighboring land uses, proximity to preserved farms, and local communities' commitment to practices contributing to sustaining farming. This automation is particularly notable in that it uses a parcel-based approach at a county-wide scale. This supports both an assessment of individual farms and a broad understanding of policy outcomes and pattern across the entire county. More interesting are the emerging pattern of benefits and barriers in the automation process highlighted by this exploration.
\end{abstract}

(c) 2002 Elsevier Science B.V. All rights reserved.

\section{Introduction}

Farmland preservation programs, particularly as implemented in the US, are spatially based policies and decision-making processes that, as yet, benefit from very limited applications of geospatial technologies. This paper explores how geographic information systems (GIS) can impact farmland preservation practices.

Farmland preservation is a complex issue in New Jersey, which earned the nickname, The Garden State, from its extensive farmland in close proximity to New

\footnotetext{
* Corresponding author. Tel.: +1-732-932-1581; fax: +1-732-932-1940.

E-mail address: dtulloch@crssa.rutgers.edu (D.L. Tulloch).
}

York city and Philadelphia (Fig. 1). The state-in the mid-Atlantic region of the US-has one of the most exacting local home-rule systems in the nation making a regionally coordinated farmland preservation strategy very challenging. Attempts at enacting a state-wide land use plan have met with vehement political opposition rendering the plan largely ineffective at mitigating sprawl and curtailing farmland loss. In the past five decades the loss of more than half of New Jersey's pre-WWII farmland (over 364,000 ha) (NJDA, 2000) to urban growth prompted the passage of the Agriculture Retention and Development Act in 1983. Under the program landowners are paid by the state to keep their property in permanent preservation. The program is funded through bond issues administered through the State Agricultural Development 


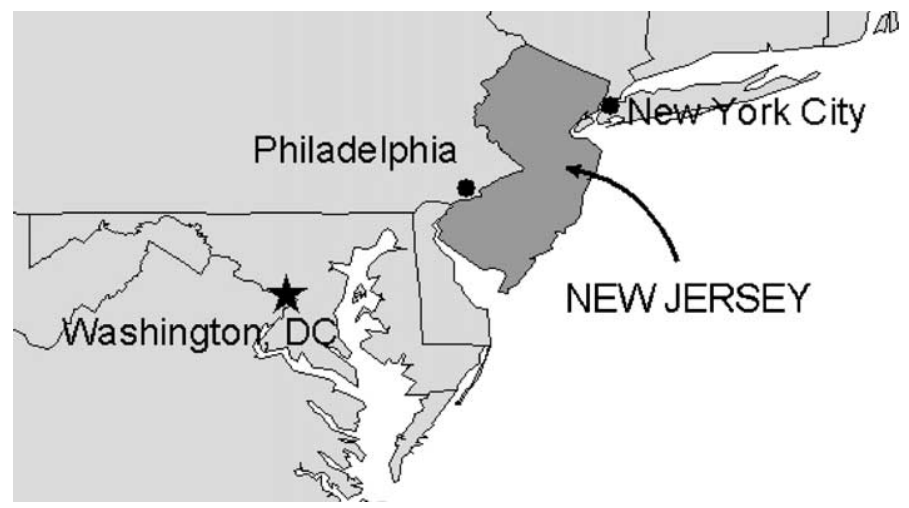

Fig. 1. A map showing the state of New Jersey's location between Philadelphia and New York city.

Committee (SADC), a governor-appointed commission of public officials and private citizens. Over the past 15 years the program has resulted in the preservation 457 farms totaling 27,248 ha of preserved farmland throughout 16 of New Jersey's 21 counties.

In 1998 the Garden State Preservation Trust program was created by a state-wide referendum, dramatically increasing preservation funding with the goal of preserving an additional 404,687 ha of open space. One-half of the million acres preservation goal is designated for farmland preservation. In the year since the program was initiated funding approval has been granted for an additional 260 farms totaling 10,462 ha (NJDA, 2000), adding over a third more farmland preservation in only a year to what had been preserved over the previous 17 years. In light of this unprecedented public investment, examination of the application of geographic information systems (GIS) to enhance the farmland preservation effort is warranted.

\section{Background}

Rapid urban and suburban growth in agricultural areas has become a familiar occurrence in many metropolitan regions (USDA, 2000). The loss of farming viability to the pressures of urban and suburban development has resulted in significant deterioration of farming economies in once agriculturally important areas (Lopez et al., 1988). A significant number of productive regions in the US have been identified as being at especially high levels of risk (Sorensen et al., 1997).

In the face of such farmland encroachment various approaches to managing agricultural land have been employed nationally as well as internationally. The Netherlands and UK are arguably the most successful international examples of farmland (or more accurately countryside) preservation (Alterman, 1997), incorporating long-term and comprehensive state-level land use controls which spring from a deep cultural land ethic. In the US, Oregon is held up as the most effective example of farmland protection, employing a long-term comprehensive land use planning system with state-level regulatory control (Nelson, 1992; Daniels, 1997; Kline and Alig, 1999; Gustafson et al., 1982). Oregon's system includes Urban Growth Boundaries to contain urban sprawl as well as Exclusive Farm Use districts in which prime farmlands are precluded from development altogether.

While it may be argued that a comprehensive system of planning with strong regulatory power as in Oregon may be the most effective strategy for preserving farmland, the political difficulties of implementing state-level land use control through regulation leave Oregon's example a lone exception to the national norm. There is virtually no direct federal involvement in comprehensive farmland planning as attempts for a federal Land Use Act failed in the 1970s and few efforts to introduce similar policies have arisen since (Popper, 1988). Instead, the federal approach to agricultural land use policy has been to implement programs that offer financial and technical assistance 
to private landowners for land conservation activities and farmland protection. Federal programs include the Farmland Protection Act of 1981, the Conservation Reserve Program (CRP), and the Conservation Reserve Enhancement Program (CREP) (USDA, 2000).

Comprehensive land use planning of farmlands is also a rarity at the state level. Only Oregon and Hawaii have state-wide policies for exclusive agricultural zoning and Hawaii's is proving less effective than Oregon's at preventing agricultural conversion to urban land uses (Ferguson and Khan, 1992). Most states leave issues of land planning and agricultural protection to regional, county and local agencies. Some notable comprehensive approaches to farmland preservation at the regional level include Montgomery County, Maryland and Lancaster County, Pennsylvania (Daniels, 1997).

While few state-wide comprehensive regulatory land planning strategies for farmland preservation exist outside of Oregon, a number of more limited fiscal and regulatory approaches have been employed and are growing in popularity throughout the nation. These include: (1) agricultural tax structuring, (2) transfer of development rights (TDR), (3) purchase of development rights (PDR), (4) right-to-farm ordinances, (5) creation of agricultural districts, (6) inclusive agricultural zoning (agricultural zoning allowing various non-agricultural uses), (7) impact fees, (8) requirement of environmental impact analysis and (9) growth management planning (Adelaja and Schilling, 1998). Other programs include agricultural buffers, regulatory relief and conservation easements (Sokolow, 1999; AFT, 1997). Many variations and combinations of these farmland preservation strategies appear to be growing in acceptance and use, particularly in rapidly urbanizing areas. While various combinations of these approaches are helping to stem the loss of agricultural lands, in many cases the conversion to urban development is simply delayed.

Some policy analysts argue against public spending for farmland preservation, contending that there is sufficient agriculturally productive land available and that land markets are the best means for efficiently allocating land use (Edgens and Staley, 1999). Whether or not it is needed, both the public and the farming community popularly support farmland preservation although usually for different reasons (Pfeffer and Lapping, 1995). Nelson (1992) suggest three rationales generally given for enacting measures of farmland protection: preservation of regionally important production capacity, such as truck farms and specialty crops that require proximity to markets; public benefits associated with farmland; and open space preservation that provides spatial definition to urban areas. Of these three goals, public preference seems to favor the open space benefit of farmland preservation (Kline and Wichelns, 1996, 1998; Nelson, 1992).

Of the various farmland preservation techniques mentioned, only transfer of development rights (TDR) and purchase of development rights (PDR) permanently preserve lands from development. TDR has had very limited success because of ineffective incentives for participation in both sending and receiving districts (Price, 1981). Only Montgomery County, Maryland and the New Jersey Pinelands-an ecologically sensitive ecosystem in the southern part of the state-have succeeded in preserving significant amounts of land through TDR (Adelaja and Schilling, 1998). PDR has emerged as the preservation approach most often taken, particularly in the Northeast (Pfeffer and Lapping, 1995). Under PDR a landowner voluntarily sells the development rights to their land, receiving payment for the development value of their land in return for a permanent restriction on further development. While the land remains in private ownership and can be bought and sold on the open market, a restrictive covenant is recorded in the deed protecting the parcel in perpetuity. A number of states have active PDR programs, with New Jersey having one of the most active.

\subsection{GIS and local government}

\subsubsection{Status and role of GIS in both FPP and local government}

While the technology is not yet ubiquitous, a large number of local governments have already adopted the technology as part of their daily functions (Masser and Campbell, 1993, 1994; Budic, 1993, 1994; Tulloch and Fuld, in press). Less is known about the specific nature and extent of local government GIS for agricultural applications, although a recent survey of geospatial data producers offers new details. The authors analyzed the Federal Geographic Data Committee's publicly released responses to the National Framework Survey repeating methodology 
already detailed elsewhere (Tulloch and Robinson, 2000; Tulloch and Fuld, in press). Of 1066 US county government respondents involved in the production of GIS data, 23\% indicated that an "agriculture" department or group was "creating, maintaining, inventorying, distributing, or using digital geographic data." (FGDC, 2001) Of these 212 respondents, none indicated that agriculture was the only department or group producing data. Nearly half (103) indicated that organizations had at least 10 different departments or groups producing digital geographic data.

The multi-agency approach to local government GIS is embedded in the concept of multipurpose land information systems (MPLIS), and is critical for most farmland preservation GIS efforts to succeed. Most characterizations of MPLIS (McLaughlin, 1975; Brown and Moyer, 1989) describe it as a land-oriented approach to GIS, building data from a variety of departments with a cadastral or parcel layer as its base. Many descriptions of MPLIS have stressed one of the most powerful attributes of GIS - the integrative ability of the technology. MPLIS often combines data describing rigid engineering features (e.g. parcel, geodetic control, and transportation data), natural resources (e.g. soils, hydrology, vegetation), and socio-economic and political phenomena (demographics, zoning, government boundaries).

While not explicitly required by most definitions, MPLIS has generally been described as operating in an environment of public access and service. This is reflected in the emerging discussion of equity and democratization (Tulloch, 1999) and public participation geographic information systems (PPGIS) (Craig et al., 2002). The degree to which access and engagement occur can vary according to circumstance including cases where citizens benefit from the technology without using it at all. Attempts to prevent access and participation can undermine the ultimate success of the system. The MPLIS serves as a useful model for farmland preservation processes because its comprehensive, integrative and engaging nature are important considerations in these complex public decisions. The public investments involved and the impact on many different members of the community raise increasing expectations about engagement of the public in the decision-making process, including the analysis and dissemination of data.

\subsubsection{Existing farmland preservation GIS applications}

The explicit role of GIS/LIS in analysis of agricultural land conversion and farmland preservation is growing. Land use models that employ techniques of geospatial analysis are providing better understanding of urban pressures on agricultural regions (Bradshaw and Muller, 1997; Levia and Page, 2000). Other land use change models have variable applicability for agricultural conversion and farmland preservation (see USEPA (2000) for a review of land use change models). Geospatial technologies are also being utilized for evaluation of agricultural value in programs such as the USDA's Land Evaluation and Site Assessment (LESA) tool (Pease and Coughlin, 1996). LESA employs a weighting and scoring system to model physical factors such as soil quality, agricultural productivity, and water availability as well as cultural factors such as economic trends and development pressures. Variations of the LESA model are being developed for applications such as review of proposed zoning changes, selection of parcels for conservation easements and farmland priority zoning (Land Information Bulletin, 2000a). Pennsylvania in particular has had significant success in implementing LESA using GIS (Land Information Bulletin, 2000b). Wisconsin also stands out as a leader in developing tools for farmland preservation programs (Jackson-Smith and Bukovac, 1998, Johnson and Jacobs, 1994).

Internationally, geospatial technologies have been used in the assessment, allocation and planning of agricultural land. As in the US, tension exists between the need for policy-specific analyses and the desire to develop more generalizable methodologies. Stoorvogel and Antle (2001) call for the development of more generic methodologies for regional land use analysis rather then engaging in ad hoc analyses. An example of the type of tool they would like to see developed can be found in the generalized framework for evaluating landscapes in Spain using GIS that has been developed by Gulinck et al. (2001). Although generalized methodologies hold significant promise for developing transferable tools, the need for scale, location and policy-specific information and methods must be considered when the time comes to apply them in specific analyses. For instance, Carsens and van der Knaap (2002) explore the utility of GIS to help solve problems of agricultural land allocation. In 
order to apply their generalized method to their two differently scaled case studies, they must make use of case dependent information and techniques. The variation in approaches to preservation from development prohibition to land use regulation to property acquisition suggests that within the larger international context much of the farmland preservation work in the US has less in common with other farmland preservation approaches than with open space acquisition systems.

\section{Hunterdon County case study}

\subsection{Hunterdon background}

Hunterdon County is a relatively rural area located in east-central New Jersey, about $1 \mathrm{~h}$ drive from New York city. In recent years the county, with a population of over 110,000, has experienced a significant boom in suburban development that has threatened some of the area's most productive farmland. The population growth during the last decade was over 10\% (US Census Bureau, 2000), but the landscape change is more dramatic because of large-lot zoning and leapfrog development.

Hunterdon County was chosen as a case study because of several attributes: significant pressure to develop farmland, an active farmland preservation program, and a comprehensive, publicly available digital geospatial database that includes county-wide parcel mapping.

\subsubsection{Existing farmland preservation program}

Hunterdon County's primary tool for long-term farmland preservation is the purchase of development rights. The New Jersey farmland preservation program is coordinated by the State Agricultural Development Committee (SADC), while the administration of the program occurs at the county level. Each county is responsible for creating a County Agricultural Development Board (CADB) representing the general and farming public, the county planning board, soil conservation district and the county agricultural extension agent. The CADB responsibilities include setting minimum standards for participation in the program, reviewing, approving and coordinating applications as well as coordinating the purchase of development easements within each municipality. While each county has flexibility in designing the details of the easement purchase criteria, all counties follow the general criteria categories of the state including: (1) likelihood of long-term agricultural viability, (2) degree of imminence of change of the land from productive agricultural to non-agricultural use, (3) special considerations for achieving program objectives, (4) relative best buy, and (5) exceptions of preservation requested. All participating counties adhere to these criteria with minor variations in implementation.

As of April 2001, the Hunterdon County farmland preservation program has permanently preserved 62,805 ha, with another 339 ha in an 8-year preservation program (Fig. 2a). The county is also experiencing significant suburban development adding 4570 ha of developed lands between 1986 and 1995 (Fig. 2b). Out of the newly developed area, 2930 ha or $64 \%$, were converted from active farmlands. These pressures make the preservation prioritization process difficult, since many of the properties under consideration have an escalating development value and the properties available for consideration continue to drop in number.

\subsubsection{Current easement purchase criteria system}

Following the state guidelines, the Hunterdon CADB developed five categorical criteria to evaluate properties for preservation. The county staff receives applications for participation in the program from interested property owners. Each applicant's property is then assigned quantitative scores for each of the five categories of criteria: soils, boundaries and buffers, local commitment, size and density, and farm and family characteristics. The categories are weighted by assigning a different number of possible points to each category (Table 1). The scoring regime used in this research was current as of August 2001.

3.1.2.1. Soils. The most heavily weighted criterion is soils, which is designed to preserve the most productive farmland. In particular, this category emphasizes areas designated as prime farmland soils, with lesser emphasis on soils of state-wide, unique, or local importance. Prime farmland soil is defined by the Natural Resources Conservation Service (NRCS, formerly the Soil Conservation Service) as soil that contributes to high sustained yields, and includes all NRCS Land Capability class 1 areas and some areas from class 2 . 


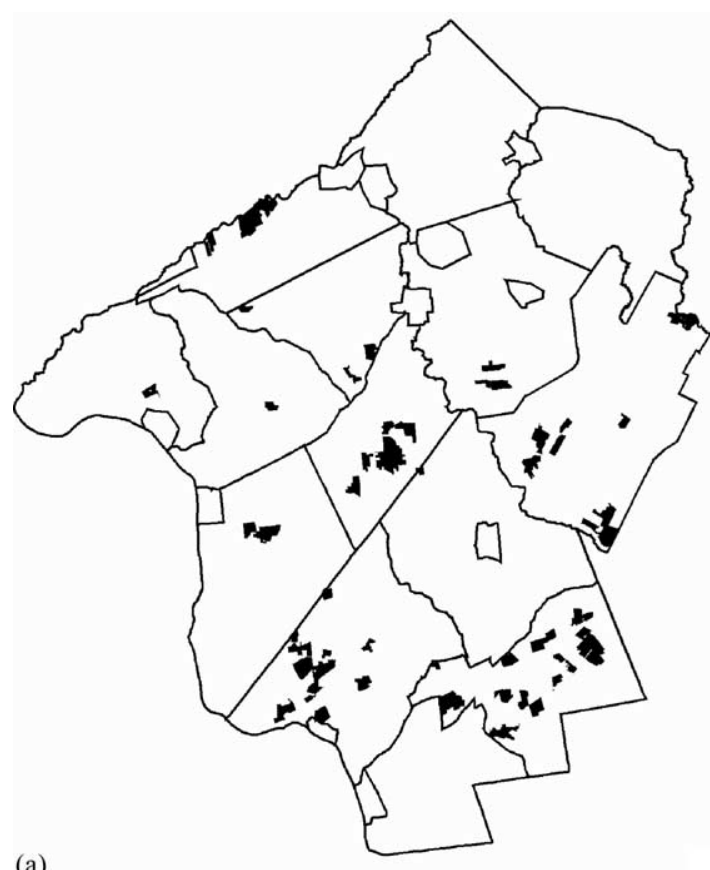

(a)

(b)

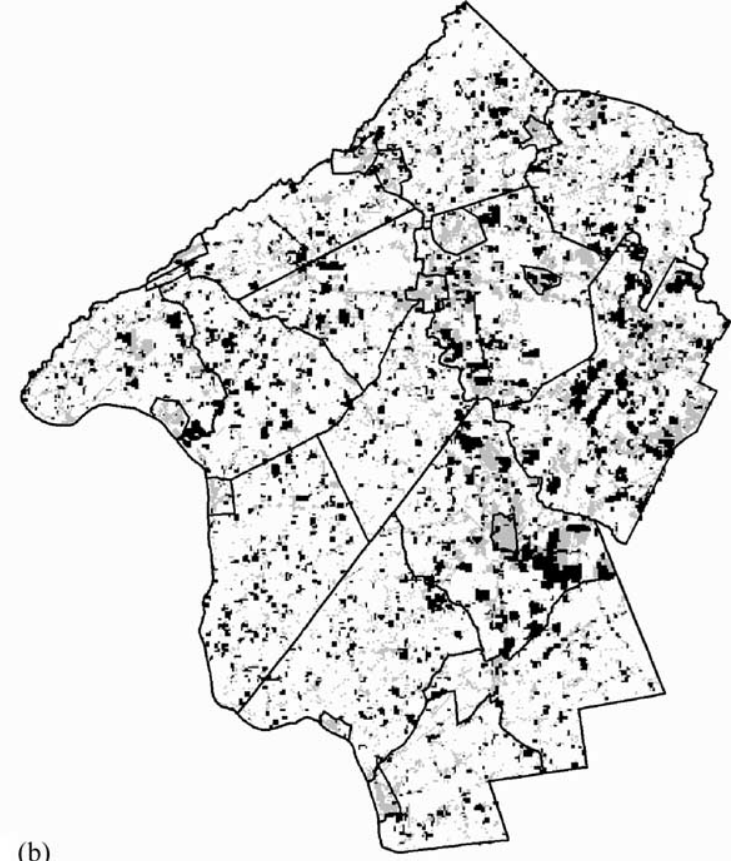

20

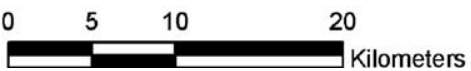

Fig. 2. (a) A map of preserved farmland in Hunterdon County, NJ. (b) A map of urban and suburban development in Hunterdon County, NJ as of 1995. The gray areas were developed before 1984 and the black areas subsequently.

Soils of State-wide importance are soils with important relationships to agricultural practices within the state.

Unique farmland is land other than prime farmland that is used for production of specific high value food and fiber crops (e.g. cranberries, nut trees). This is, in part a definition based on current farming practices,

\section{Table 1}

The Hunterdon County, NJ farmland preservation assigns the following point for their five categories of criteria (as of August 2001)

\begin{tabular}{lc}
\hline Category of criteria & Points \\
\hline Soils & 30 \\
Boundaries and buffers & 20 \\
Local commitment & 22 \\
Size and density & 24 \\
Farm and family characteristics & 10 \\
Total & 106 \\
\hline
\end{tabular}

since the land so designated must actually be used for growing these specific high value crops. Farmland of state-wide importance has soils in land capability classes 2 and 3, and does not qualify as prime but can economically produce high yields of crops when treated and managed according to acceptable farming methods.

The point allocation system for agricultural soils is manually derived from county soil surveys on a parcel basis for the applicant farm. The calculation formula allocates up to 30 points based on the quality of soils present on a farm. A farm that is exclusively prime soils would get all 30 points, while a farm of exclusively locally important soils would only get 10 points.

3.1.2.2. Boundaries and buffers. A property's value to the community for preservation is impacted by its neighboring properties. The boundaries and buffers criterion assigns value to properties based on land uses 
Table 2

For the 20-point boundaries and buffers criterion, properties are evaluated by the land use of the adjacent properties

\begin{tabular}{lc}
\hline Adjoining land use & Percent of perimeter multiplied by \\
\hline Deed restricted farmland in permanent preservation & 20 \\
Deed restricted wildlife areas, municipal, county or state owned parcels & 18 \\
Parcels in eight year preservation program & 13 \\
Farmland (unrestricted) & 6 \\
Streams (perennial) and wetlands & 18 \\
Parks (passive recreation) & 14 \\
Parks (high use) & 5 \\
Golf courses (publicly owned or deed restricted) & 14 \\
Military installations & 14 \\
Highways (limited access) and railroads & 10 \\
Cemeteries & 16 \\
Farm parcels applying for permanent preservation & 9 \\
Residential development & 0 \\
Other (landfills, private golf courses, etc.) & Determined on a case by case basis
\end{tabular}

Points are allocated to applicants based on the following adjacent land uses.

of neighboring parcels. A maximum of 20 points is allotted for application parcels with adjacent land uses that will benefit or be conducive to continued agricultural viability. The criteria are based on the length of adjoining beneficial land use in relation to the entire parcel perimeter. Various land uses are weighted differently to reflect the relative benefit (Table 2). The highest ranking is assigned to properties adjacent to deed restricted farmland in permanent preservation, while no points are given for adjacency to residential property.

3.1.2.3. Local commitment. Hunterdon County is composed of 26 municipalities with relatively autonomous land use and zoning powers. The CADB rewards those municipalities whose commitment to the rural landscape reinforces the farmland preservation program. A maximum of 22 points are given for the degree to which the local municipality actively participates in measures beneficial to long-term agricultural survivability. The points are awarded based on individual practices employed by communities, including specific zoning ordinances, sewage plans, and right-to-farm ordinances (Table 3).

3.1.2.4. Size and density. Long-term agricultural survivability hinges, in part, on preserving farmland in contiguous clusters. To promote these larger areas

Table 3

As part of the local commitment criterion, points awarded to applicants based on the following community practices that promote or limit the success of the farmland preservation program

\begin{tabular}{lll}
\hline Criteria & Explanation & Points awarded \\
\hline Zoning & $\begin{array}{l}\text { Zoning measures which provide creative means for farmland } \\
\text { preservation such as transfer of development rights (TDR), agri- } \\
\text { cultural zoning with low residential density, mandatory buffers } \\
\text { along agricultural boundaries and/or any other equivalent measures }\end{array}$ & 5 \\
& which discourage conflicting nonagricultural development & \\
& Parcels which are not within service area of existing or planned & 3 \\
Sewer non-accessibility & sewer service are allocated & 2 \\
Consistency & Municipal commitment to actively participate in the Agricultural Re- & Up to 5 \\
Municipal commitment & tention and Development Program & 4 or 5 points \\
Right-to-farm ordinance & & 2 \\
Municipal cost sharing of program & &
\end{tabular}


of farmland, the Hunterdon CADB has identified size and density criteria. A maximum of 24 total points are awarded to applicants based the size of the parcel and the number of preserved parcels within the local region.

The scoring system for size and density requires significant spatial measures. To encourage the preservation of larger farms, 12 points are given for farms equal to or greater than twice the county average farm size. Applicant parcels smaller than twice the county average are awarded proportionately fewer points. Properties are awarded up to 12 points for being in a densely farmed area. An applicant is awarded 1 point for each farm in permanent preservation and 2 points for each concurrent application within $0.8 \mathrm{~km}$.

3.1.2.5. Farm and family characteristics. The farm and family characteristics criteria award up to 10 points for on-site conditions favorable to long-term agricultural sustainability (Table 4). This category is comprised of four specific criteria: percentage of land actively cropped or grazed, soil conservation measures, good farm management practices, and on-site farming investments. Soil conservation is the most heavily weighted of the four criteria.

\subsection{Automation of point allocation system}

The criteria used for evaluating farmland properties for easement purchase were designed to provide a fair, equitable and objective means for allocating public funds. To date, Hunterdon County has largely used manual processes for the calculation of evaluation criteria on a parcel-by-parcel time intensive process with minor (although increasing) use of GIS for assistance. The point allocation for each property is performed after the application is completed and submitted. The

Table 4

Farm and family characteristics is the single criterion that is not appropriate for automation

\begin{tabular}{ll}
\hline Farm and family characteristics & Points \\
\hline Percentage of land actively cropped or grazed & 2 \\
Soil conservation measures & 3.5 \\
Good farm management practices & 2.5 \\
On-site farming investments & 2 \\
\hline
\end{tabular}

Points are awarded to applicants based on the following farm and family characteristics. inefficiency of this manual calculation system precludes parcel owners from having an understanding of their position among other farms within the ranking system before the intensive application process is completed. It also prevents the generation of information indicating where highly ranked parcels, not yet preserved, may be located for better and more comprehensive farmland preservation planning. A major objective of this research was to explore the feasibility of an automated system designed to calculate preservation points for all parcels throughout Hunterdon County following the existing county easement purchase criteria. This "wall-to-wall" assessment would facilitate a pro-active approach to farmland preservation planning by allowing evaluation of all parcels.

Automation of the point allocation system was performed with publicly available data in a geographic information system (GIS) using a combination of ESRI software products (ArcINFO, ArcView, Spatial Analyst and GRID). A county-wide parcel coverage was created by the Hunterdon County Planning Department. A separate tax database and zoning lookup table was joined to the parcel coverage. Various other data themes including roads, railroads, hydrology and open space were also provided by the county. Freshwater wetlands, 1995-1997 land use/land cover and digital orthophotoquads were provided by the New Jersey Department of Environmental Protection. County soils coverages were acquired from the Natural Resource Conservation Service (NRCS) (formerly Soil Conservation Service).

\subsubsection{Automation of soils criteria}

Soil points were created by first extracting the soil categories from the NRCS soils coverage. The soils were classified into prime, state-wide, unique and local, categories. The categories were respectively tagged with their corresponding point values of 30 , 20, 25 and 10. This modified soils coverage was then converted to a raster or gridded format. A tabulation of areas between the parcels and the gridded soils coverage resulted in a summary table for the acreage of each soil categories within each parcel. This summary table was then rejoined back to the original parcel coverage providing the total acres of each soil class within each parcel. Finally, a new field was generated for the parcel coverage for total soil points. The ownership parcel served as the basic geographic 
unit of interest. The field was calculated using the joined soils classification acreage and the following formula (formula 1):

$\mathrm{SP}=\frac{(\mathrm{Pr} \times 30)+(\mathrm{St} \times 20)+(\mathrm{Uq} \times 25)+(\mathrm{Lo} \times 10)}{\mathrm{Ap}}$,

where Pr denotes the acres prime soil, St the acres state important soil, Uq the acres unique soil, Lo the acres locally important soil, Ap the parcel area.

\subsubsection{Automation of boundaries and buffers criteria}

The boundaries and buffers criteria proved to be the most challenging category to automate. The difficulties arose from several factors including that many of the features incorporated in boundaries and buffers calculation were not necessarily immediately adjacent to each parcel boundary. This was particularly true for parcels which were adjacent across road breaks as well as for features such as wetlands and streams which did not necessarily run directly along property lines.

To address the difficulty of gaps in adjacency, all boundary and buffer feature layers (i.e. preserved parcels, deed restricted wildlife areas, farmland, parks, etc.) were buffered by $22.86 \mathrm{~m}$, a distance that spanned all road gaps with the exception of the largest state roads. Each of these buffered layers was converted to a grid and coded with its assigned weighting for the point value of each criterion and overlaid to produce a maximum value grid layer. Since the parks high-use and residential criteria take precedence even though they may be lower values than other maximum values for a location, they were added back as masks overlays to result in the final boundary and buffers cumulative value layer.

The final step entailed calculating the value of the cumulative value layer for the bounding peripheral edge of each parcel polygon. A methodology was developed in which gridded parcel boundaries were generated on the interior side of each parcel polygon. This gridded boundary represented the perimeter of each parcel and was subsequently overlaid with the cumulative value layer to produce a perimeter value layer. Summarizing the perimeter value layer by the original vector parcel coverage resulted in the final boundary and buffer valuation by parcel. Fig. 3 presents a conceptual model of this process.

\subsubsection{Automation of local commitment criteria}

Local commitment points are calculated as a single value for each municipality (Formula 2). For

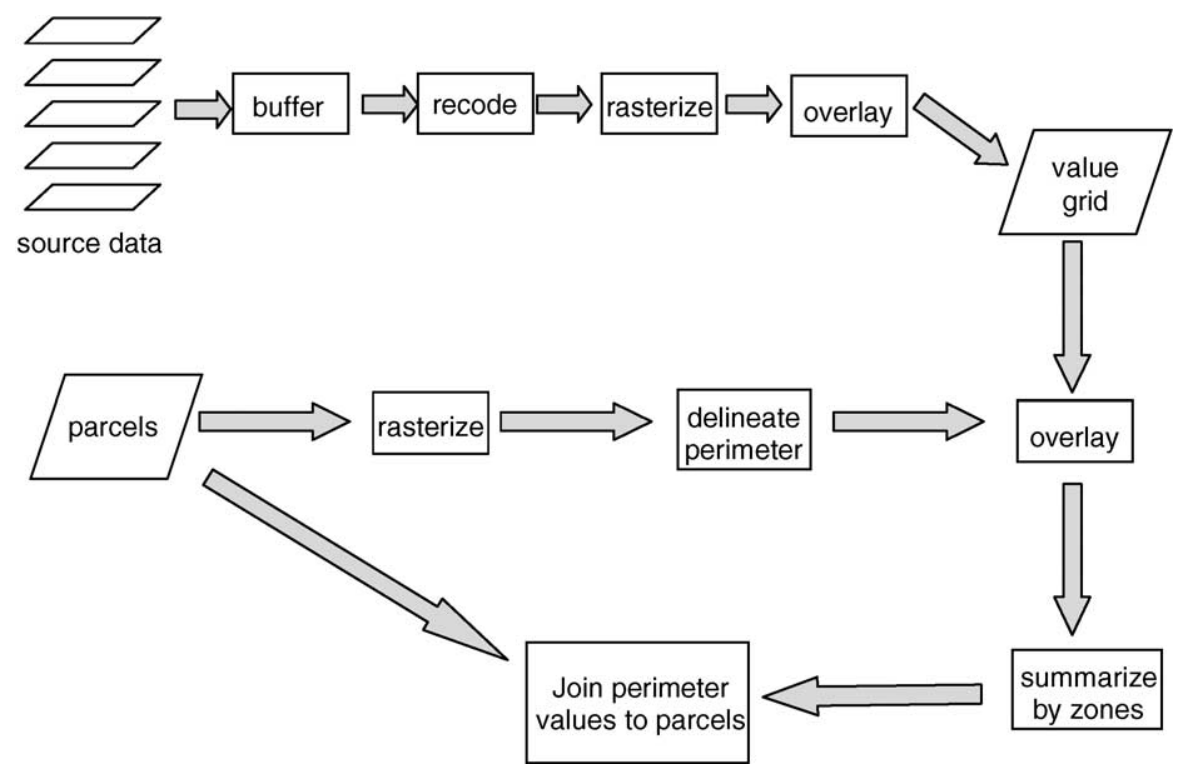

Fig. 3. A conceptual diagram of the process for determining the point allocations for boundaries and buffers criteria. 
consistency with the manual criteria calculation the local commitment for each parcel was simply assigned from a table provided by the county. This method of calculation, however, disregards some of the parcel-specific local commitment points such as proximity to sewer service.

$\mathrm{LCP}=$ Lclut

where LCP denotes local commitment points and Lclut the local commitment points from county lookup table.

\subsubsection{Automation of size and density criteria}

The size and density criteria required two distinct sets of spatial analysis. Size was calculated following the program formula (Formula 3 ) on the polygon areal size. This method, however, was somewhat limited in the respect that single farms sometimes consist of multiple parcels. This size point factor would need to be cumulative if any potential application contained multiple parcels.

If : $\mathrm{Ap}>\mathrm{Cafs} \times 2$, Then : $\mathrm{SP}=12$,

Else SP $=\frac{\mathrm{Ap}}{\mathrm{Cafs} \times 2} \times 12$

where SP denotes the soil points, Ap the area of parcel and Cafs the county average farm size.

Density was calculated by converting the polygon coverages for permanently preserved parcels as well as concurrent applications into a GRID coverage. A $0.8 \mathrm{~km}$ neighborhood analysis function was then performed on each of the preserved and applicant gridded coverages using the neighborhood diversity function. This provided an output grid in which each cell contained the total number of different preserved farms within the $0.8 \mathrm{~km}$ search radius.

These diversity grids were then overlaid back with the original polygon parcel coverage using a summarize by zone command. The maximum value field representing the highest count of different preserved farms within $0.8 \mathrm{~km}$ of each grid cell was then joined back to the parcel coverage to provide a density count of preserved and applicant farms. This count was then translated into the density score for each parcel using the following formula (Formula 4):

If : $\operatorname{Pfp}+2 \times$ Pap $<12$,

Then : DP $=$ Pfp $+2 \times$ Pap, Else $:$ DP $=12$ where DP denotes the density points, Pfp the number of parcels in preservation within $0.8 \mathrm{~km}$, Pap the number of parcels applying for farmland preservation within $0.8 \mathrm{~km}$.

\subsubsection{Automation of farm and family criteria}

The nature of the farm and family characteristics is such that they cannot easily be automated. Since they currently represent less than 10 percent of the total scoring, this does not effectively undermine the automation but it does reinforce concerns about integration of non-spatial criteria into the process.

\subsubsection{Compilation of scores}

The traditional process of tabulating scores is based on a simple addition of the individual criteria scores. The traditional technique used by the planning staff is to manually calculate scores only for the farms whose owners have applied for consideration in the most recent round of PDR acquisitions. With GIS, the calculations can be made for every property in the county including properties that are ineligible for consideration (like public lands, developed properties, and those outside the ADAs). When the scores are mapped (Fig. 4), the result is a surface of varying value that shows areas of high value, but also shows the lack of homogeneity in even the "best" agricultural areas.

\subsection{Comparison of manual and automated techniques}

An important outcome of the case study is the ability to compare the existing manual technique with the automated technique. This comparison can occur on both a qualitative and a quantitative level, with each producing a different understanding of the differences.

The simplest comparison is the quantitative measure of how the two approaches compare. The authors used recent scores generated manually by the Hunterdon planning staff as a basis for comparison with the computer generated scores. Of the 106 potential points to be awarded, the automated technique can address 96 . Many applicants have multiple parcels that are considered as one farm for point allocation. This makes a direct comparison for such parcels problematic for analysis. A selected set of single parcel preservation was therefore used the compare three of the criteria. Another issue that causes the automated calculation to 


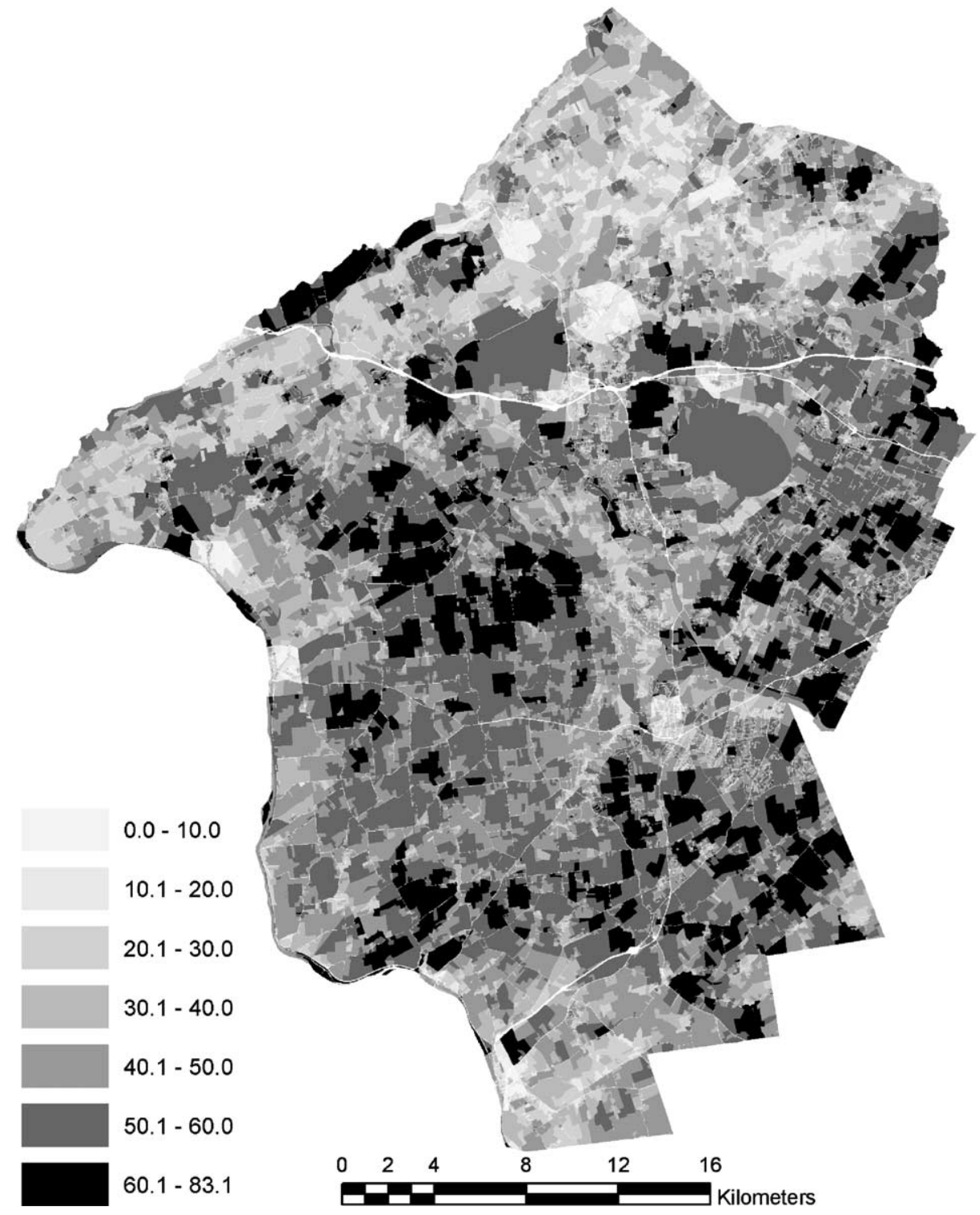

Fig. 4. A map of total scores for every property in Hunterdon County, NJ. This includes the calculation of scores for properties that are otherwise unsuitable, such as developed lands and open water. However, the map serves to illustrate the larger patterns across the landscape.

differ from a manual calculation is the calculation for current applicants. A number of the criteria are dependant on the current application pool including density and boundaries and buffers. Since the future applicant pool cannot be known a priori, this results in boundary and buffers not having the values that would be added for adjacent applications.
A qualitative comparison shows that the manual techniques may not be as accurate as the automated approach for some criteria. In trying to replicate the process, we found that some of the criteria would be nearly impossible to score accurately using manual techniques. In almost every case, the manual evaluation of farms within the limited time constraints of 
the program introduces significant added potential for error. Conversely, the experimental automation also demonstrates the inability of GIS to capture criteria that require evaluation and assessment of site conditions by humans who possess specialized knowledge.

\section{Results and discussion}

\subsection{Overview}

The automation of the process was conducted, in part, as an experiment in the ways that technology could be integrated into the farmland preservation process. Through the process of implementing this experiment, a number of patterns have begun to emerge with implications for the use of similar automation in other FPPs or open space prioritization programs. Much was learned about the barriers to automation of FPP, and the difficulties that must be overcome in such a process. Other patterns highlight the areas for potential successes in automating this process and provide evidence suggesting that the difficulties may be worth the extra effort.

\subsection{Barriers to automation of the farmland preservation process}

Our first finding is not a surprise; automating the property evaluation or scoring technique for farmland preservation is a difficult and cumbersome process. This finding reflects several barriers including: criteria that do not lend themselves to automation; a lack of needed data; a lack of support (financial, political, and technical); and a lack of defined goals. Some of these are based on patterns emerging from direct experiences of the research team, while others are based more on observations of what would be expected to occur in other locales or situations.

A major problem in automating the process is that some of the criteria in our case study are simply not easily translated into the sorts of spatial analysis for which a GIS is employed. The simplest example is the entire category of farm and family criteria which change so frequently that they would not be likely to be stored in a long-term database, and in fact would generally require that the applicant answer questions about the criteria in order for a score to be calculated. It seems likely that other counties could include even more difficult criteria like the condition of farm equipment and structures, or the scenic value of the property. Of course, such criteria require farm-by-farm assessment whether other criteria are automated or manually calculated.

Although Hunterdon County maintains a relatively sophisticated and robust GIS database, the research team found a variety of spatial data that had to be developed specifically for the purposes of this project. For example, data regarding certain land uses (like golf courses) and the local commitment data had to be generated independently. Most counties would still need to develop spatial databases of parcels and soils of such quality that they could support this public decision process.

Any implementation of this automation within a county government setting would also require substantial support. A research grant provided funding that would not normally be available for a county government interested in pursuing automation. Similarly, an existing university research facility provided technical support at a level that is extremely uncommon. Political support would clearly be needed to provide the funding and technical support, as well as the institutional provision of high-quality, current data. However, there is no technical barrier present that would prevent a county with appropriate digital data-particularly parcel, soils, and land use-from being able to automate its process.

Finally, we found that there was an increased need for clearly stated goals to be achieved by the program. While the existing criteria guidelines were sufficient for the manual allocation of points, several criteria left room for interpretation that only became apparent when the rules are applied to tens of thousands of parcels instead of just a handful. An automated process would benefit greatly from clarifying definitions and criteria so that the spatial data can be developed in ways that fully satisfy the intentions of the CADB.

\subsection{Benefits of automation of the farmland preservation process}

We found that, despite the previously described barriers to implementation, the automation of the farmland preservation prioritization process is a reasonable and beneficial process. The pattern of benefits 
observed suggests a far-reaching impact of automation. We observed a number of benefits including reductions in errors in calculating the score, more objective scoring, the ability to add additional criteria, the ability to integrate FPP with other spatial policies (like zoning and tax incentives), and a much faster and easier calculation of scores. Ultimately these benefits could result in a more open and transparent planning process and an increased community confidence/perception of fairness.

As it is practiced today, the CADB staff relies significantly on traditional map products and manual measurement of many of the spatial criteria. Although the percentage of different categories of soils on a farm can be manually tracked using a planimeter, they can be measured much more accurately (and faster) with the computer. More difficult for the staff would be measures of the number of preserved farms within a half-mile. The opportunities for both spatial inaccuracy and miscalculation with the manual techniques make the GIS-based approach seem particularly beneficial in competitive and high visibility decisions.

The current process places a certain degree, albeit limited, of subjective decision making in the hands the planning staff. Judgment calls are required for several categories of criteria, with little opportunity to explain the subjectivity. As professionals, these planning technicians are assumed to be skilled in controlling their biases, but the human condition is such that accidental or unconscious bias does affect decisions. An automated approach forces the subjective components to be made consistently. It also makes it easier for affected parties to examine the ways in which those elements impacted the larger decision.

The sophistication of the technology allows the introduction of new criteria and analyses that would be effectively impossible using traditional methods. An example would be data relying on complex modeling. One example would be an increased incorporation of evaluation techniques like LESA and RUSLE, which could be calculated quickly for individual fields as well as overall parcels. Another would be the development of a reiterative econometric model, allowing for more accurate prioritization of properties based on their likelihood of development.

Technology advocates often point to the integrative abilities of GIS as one its strongest attributes. Farmland preservation projects could benefit greatly from the increased integration of data about other programs and policies. As land conservation and land use planning policies actively shape the landscape, the staff could integrate these data directly into the process. Ultimately this automation could support the integration of multiple open space policies to shape a comprehensive preservation program.

Finally, the automation provides a communication tool with surprising ability to describe the larger condition of the program. The map products of GIS illustrate county-wide patterns that serve to inform the planning staff in new ways. They can highlight areas of emphasis that can direct new strategies for enlisting the most important unprotected farms. Or can they can show areas with notably low or high scores that conflict with the intentions of the program, thereby informing the $\mathrm{CADB}$ of problems with the scoring criteria.

\subsection{Transferability and generalizability}

An interesting pattern that emerged is the similarity between the farmland preservation process and other preservation processes. The methods developed for use in this project have the potential to be easily transferred to analyses of other preservation programs, provided they are based on parcels or similarly delineated pieces of land, as would TDR and other PDR programs. Because landowners in the US are usually entitled to receive compensation for the restriction of development rights on their land (Alterman, 1997), many farmland preservation programs in the US involve parcel-based assessments and therefore can directly benefit from the methods we have developed. In countries where development rights are not automatically granted to the landowner, our methods may not be immediately applicable to farmland preservation programs if they preserve farmland by restricting development through regulatory control. However, our methods should be generalizable to other situations where continuous surface data such soils and land cover needs to be associated with areally delineated units of management, production or ownership.

\section{Conclusions}

Based on the findings of this initial experiment, the authors encourage several new actions. There is little 
expectation that an automated process should eliminate the role of the staff in the process of evaluating applicants. On-site visits are necessary to evaluate annually changing farming practices, the condition of the farm, and the commitment to farming practices. The blind selection of properties for preservation would ultimately be a troubling process. Instead, the staff provides valuable knowledge about properties, owners, and practices that cannot easily be captured in a database. The county agricultural development board, as a political institution, must provide invaluable insights about their community's priorities. Even in an automated preservation program, the staff and board should be involved in an open and visible checking and nudging of data, and careful adjustments of criteria to keep the process working at its best.

Having shown the potential successes and barriers of automated farmland preservation activities, there is clearly a need for continued experimentation with specific ways that geospatial technologies can improve these important public programs. By making the preservation process more transparent, these technologies have the potential to reduce some of the contentiousness surrounding farmland preservation programs (Bunce, 1998, Lehman, 1995). Among the experiments that should move forward are those that explore new criteria and analyses that can help the prioritization process appropriately impact the complex land development processes occurring today. In some cases, this might really be the development of criteria to better reflect the existing goals of the program. This might also include the development of entirely new criteria not before considered possible, such as measures of susceptibility to development or value as a visual resource. Additionally, the integration of non-agriculturally oriented criteria may increase the public's acceptance and support of farmland preservation (Kline and Wichelns, 1996). The processes described in this paper could also be applied to other preservation processes, including other types of open space acquisition and PDR programs.

Finally, this early experiment demonstrates the importance of organizational and institutional support of the technology in encouraging its successful integration into existing programs. Even in a sophisticated county government setting, data availability can be a problem. For a program-like this farmland preservation acquisition program-to become successful over time, it needs to see geospatial data production and maintenance become as institutionalized as roads maintenance or police protection. In particular, high quality parcel mapping is needed to support so many of the land planning activities that occur in local government. The reason for this is simple: most major land-based decisions are made at the parcel level.

This project also demonstrates a great value for public agencies that share their data with outside organizations. While New Jersey law does allow local governments a certain degree of freedom in charging access fees for digital public data, Hunterdon County has instead allowed access at little or no cost. It is this public access to data that encourages exploration of applications, such as this farmland preservation project or environmental conservation. It will also be that same access that can permit citizens, or citizen groups, to investigate the way their taxes are being invested.

\section{Acknowledgements}

This project has been made possible in part by funding through the Rural Development section of the USDA National Research Initiative Competitive Grants Program. It also would not have been possible without spatial data from the Hunterdon County Geographic Information Systems Division and farmland preservation policy information from the staff of the Hunterdon County Agriculture Development Board.

\section{References}

Adelaja, A.O., Schilling, B.J., 1998. Innovative approaches to farmland preservation. In: Furuseth, O.J., Lapping, M.B. (Eds.), Contested Countryside: The Rural Urban Fringe in North America. Ashgate Publishing Company, Brookfield, VT.

Alterman, R., 1997. The challenge of farmland preservation: lessons from a six-nation comparison. J. Am. Plann. Assoc. 63, 220-243.

American Farmland Trust, 1997. Saving American Farmland: What Works. American Farmland Trust, Northampton, MA.

Bradshaw, T.K., Muller, B., 1997. Impacts for rapid urban growth on farmland conversion: application of new regional land use policy models and geographical information systems. Rural Sociol. 63, 1-25.

Brown, P.M., Moyer, D.D. (Eds.), 1989. Multipurpose Land Information Systems: The Guidebook. Federal Geodetic Control Committee, Washington, DC. 
Budic, Z., 1993. GIS use among southeastern local governments. J. Urban Regional Inform. Syst. Assoc. 5 (1), 4-17.

Budic, Z., 1994. Effectiveness of geographic information systems in local government planning. J. Am. Plann. Assoc. 60, 244263.

Bunce, M., 1998. Thirty years of farmland preservation in North America: discourses and ideologies of a movement. J. Rural Stud. 14, 224-233.

Carsens, G.J., van der Knaap, W., 2002. Strategic land-use allocation: dealing with the spatial relationships and fragmentation of agriculture. Landscape Urban Plann. 58, 171-179.

Craig, W., Harris, T., Weiner, D. (Eds.), 2002. Community Empowerment, Public Participation and Geographic Information Science. Taylor and Francis, London.

Daniels, T.L., 1997. Where does cluster zoning fit in farmland preservation? J. Am. Plann. Assoc. 63, 129-137.

Edgens, J.G., Staley, S.R., 1999. The Myth of Farmland Loss. Forum for Applied Research and Public Policy, Knoxville, TN.

Federal Geographic Data Committee, 2001. http://www.fgdc. gov/framework/ (accessed 30 October 2001).

Ferguson, C.A., Khan, M.A., 1992. Protecting farm land near cities: trade-offs with affordable housing in Hawaii. Land Use Policy, (10) 259-271.

Gulinck, H., Mugica, M., de Lucio, J.V., Atauri, J.A., 2001. A framework for comparative landscape analysis and evaluation based on land cover data, with an application in the Madrid region (Spain). Landscape Urban Plann. 55, 257-270.

Gustafson, G.C., Daniels, T.L., Shirack, R.P., 1982. The Oregon Land Use Act: implications for farmland and open space protection. J. Am. Plann. Assoc. 48, 365-374.

Jackson-Smith, D., Bukovac, J., 1998. Limitations of agricultural land use planning tools in rural Wisconsin. In: Proceedings of the Paper Presentation at the Annual Meeting of the American Collegiate Schools of Planning (ACSP), Atlanta, GA, 1-5 November 1998.

Johnson, S.E., Jacobs, H.M., 1994. Public education for growth management: lessons from Wisconsin's farmland preservation program. J. Soil Water Conserv. 49, 333.

Kline, J.D., Alig, R.J., 1999. Does land use planning slow the conversion of forest and farm lands? Growth Change 30, 3-22.

Kline, J., Wichelns, D., 1996. Public preferences regarding the goals of farmland preservation programs. Land Econ. 72 (4), 538-549.

Kline, J., Wichelns, D., 1998. Measuring heterogeneous preferences for preserving farmland and open space. Ecol. Econ. $26,211-224$

Land Information Bulletin, 2000a. Farmland Preservation and GIS: A Model for Deriving Farmland Priority Zones. Technical Paper No. 3. University of Wisconsin-Madison Land Information and Computer Graphics Facility, Madison, WI.

Land Information Bulletin, 2000b. Farmland Protection and GIS: GIS Interface Helps Pennsylvania Counties Prioritize Farmland for Preservation. National Consortium for Rural Geospatial Innovations, Chesapeake, Pennsylvania State University, University Park, PA.

Levia, D.F., Page, D.R., 2000. The use of cluster analysis in distinguishing farmland prone to residential development: a case study of Sterling, Massachusetts. Environ. Manage. 25, $541-548$

Lehman, T., 1995. Public Values, Private Lands: Farmland Preservation Policy, 1933-1985. University of North Carolina Press, Chapel Hill.

Lopez, R.A., Adelaja, A.O., Andrews, M.S., 1988. The effects of suburbanization on agriculture. Am. Agric. Econ. Assoc, 346-358.

Masser, I., Campbell, H., 1993. The impact of GIS on local government in UK. In: Mather, P.M. (Ed.), Geographical Information Handling: Research and Applications. Wiley, New York.

Masser, I., Campbell, H., 1994. Monitoring the take-up of GIS in British local government. In: Salling, M. (Ed.), Proceedings of the 1994 Urban and Regional Information Systems Association Annual Conference, (1) 745-754.

McLaughlin, J., 1975. The Nature, Design, and Development of Multi-Purpose Cadastres. Ph.D. Dissertation, University of Wisconsin-Madison, Madison, WI.

Nelson, A.C., 1992. Preserving prime farmland in the face of urbanization: lessons from Oregon. J. Am. Plann. Assoc. 58, 467.

Pease, J.R., Coughlin, R.E., 1996. Land Evaluation and Site Assessment: A Guidebook for Rating Agricultural Lands, 2nd ed. United States Department of Agriculture, Washington, DC.

Pfeffer, M.J., Lapping, M.B., 1995. Public and farmer support for purchase of development rights in the metropolitan Northeast. J. Soil Water Conserv. 50, 30-34.

Popper, F.J., 1988. Understanding American land use regulation since 1970: a revisionist interpretation. J. Am. Plann. Assoc. 54, 291-301.

Price, D.J., 1981. An economic model for the valuation of farmland TDRs. Appraisal J. 49, 547-556.

Sokolow, A.D., 1999. Protecting Farmland in the United States: An Outline of Optional Policy Strategies and Techniques. University of California Cooperative Extension, Davis, CA.

Sorensen, A.A., Greene, R.P., Russ, K., 1997. Farming on the Edge. American Farmland Trust, Washington, DC.

Stoorvogel, J.J., Antle, J.M., 2001. Regional land use analysis: the development of operational tools. Agric. Syst. 38, 623-640.

Tulloch, D.L., 1999. Theoretical model of multipurpose land information systems development. Trans. Geographic Inform. Syst. 3, 259-283.

Tulloch, D.L., Fuld, J., in press. County-level production of framework data: pieces of a national spatial data infrastructure? J. Urban Regional Inform. Syst. Assoc.

Tulloch, D., Robinson, M., 2000. A progress report on a US national survey of geospatial framework data. J. Govern. Inform. 27, 285-298.

United States Environmental Protection Agency, Projecting Land-Use Change: A Summary of Models for Assessing the Effects of Community Growth and Change on Land-Use Patterns. US Environmental Protection Agency, Office of Research and Development, EPA/600/R-00/098, Cincinnati, $\mathrm{OH}$.

US Census Bureau 2000. http://www.census.gov/ (accessed 30 September 2001). 
USDA Policy Advisory Committee on Farm and Forestland Protection and Land Use. Maintaining Farm and Forestland in Rapidly Growing Areas. December 2000.

David L. Tulloch is an assistant professor of landscape architecture at Cook College, Rutgers, The State University of New Jersey. $\mathrm{He}$ also serves as the GIS Program Leader at the Grant F. Walton Center for Remote Sensing and Spatial Analysis. He holds a $\mathrm{PhD}$ in land resources from the University of Wisconsin-Madison, in addition to a MLA from Louisiana State University and a BSLA from the University of Kentucky. His research interests have focused on the impacts that institutional GIS can have on landscape planning.

James R. Myers (Jim) is a graduate student in the Geography Department at Rutgers, The State University of New Jersey. He combines a background in both human ecology and natural resource management with professional experience using GIS to plan for the conservation of endangered species. His current research interests involve the use of geospatial technologies to assess and predict of the landscape-level ecological consequences of open space and farmland preservation efforts.

John E. Hasse is an assistant professor of geography at Rowan University, Glassboro, New Jersey where he teaches courses in geography, geographic information systems and planning. He received his $\mathrm{MS}$ and $\mathrm{PhD}$ in geography from Rutgers University as well as a MS in planning from the Edward J. Bloustein School of Planning and Public Policy. His professional interests are in landscape-scale analysis of urban sprawl, ecological planning and environmental geography.

Peter J. Parks is an associate professor and he has served on the faculties of Duke University, Gothenburg University, Rutgers University, and the Swedish University of Agricultural Sciences. Dr. Parks's research efforts have analyzed agricultural, resource, and environmental policies, including those designed to preserve agricultural open space, protect habitat for biologically diverse species, sustain wetland ecosystems, offset carbon emissions, and reduce erosion.

Richard G. Lathrop is an associate professor in the Department of Ecology, Evolution and Natural Resources. He serves as director of the Grant F. Walton Center for Remote Sensing and Spatial Analysis. He holds a PhD in environmental monitoring and MS in forestry from the University of Wisconsim-Madison, in addition to a BA in biology from Dartmouth College. His research interests have focused on the application of geospatial technology to the study of the causes and consequences of land use/land cover change. 